AAOUJ

11,2

136

\section{Prolonged time taken to complete the degree programmes at the Faculty of Engineering Technology of the Open University of Sri Lanka Barriers and remedies}

\author{
Shriyangi Aluwihare and Shammi De Silva \\ Department of Civil Engineering, \\ The Open University of Sri Lanka, Kandy, Sri Lanka
}

\begin{abstract}
Purpose - It has been observed that the students attending the bachelor's degree programmes offered by the Faculty of Engineering Technology (FET) at the Open University of Sri Lanka (OUSL) take extraordinarily longer period to complete their degrees. The purpose of this paper is to identify the institutional barrier, student-related personal barrier and psychological barrier behind the prolonged duration of completion of the said degrees.

Design/methodology/approach - A well-developed questionnaire was administered among a selected sample of graduates who were awarded the Bachelor of Technology (Engineering) and Bachelor of Industrial Studies degrees within the past ten years.

Findings - Results indicate that institutional barriers such as poor academic counselling and guidance; laboratory sessions being inappropriate/not sufficient to understand the course material; inadequate facilities, such as library resources, and lack of laboratory facilities at the regional centres have contributed immensely to the lengthy duration taken to complete the degrees. Personal factors such as work-related challenges, travelling time and cost of commuting to the main centre located in Colombo and inability to spend the required time expected of the programme have played major roles in the prolonged completion. Results indicate that the cost of tuition is not a major barrier for on-time completion. Psychological barriers such as possessing a limited repertoire of study strategies, lack of understanding of open and distance learning (ODL) methods and deficiency of continuous motivation had a tremendous impact on the delayed graduation. A high satisfaction rate was observed regarding the ODL tools that were used within the programmes and the formative and summative evaluation criteria. Approximately 75 per cent of the sample approved of the five remedies suggested.

Originality/value - Findings of this study provide insight for shortening the duration of the bachelor's degree programmes offered by the FET at the OUSL.
\end{abstract}

Keywords Time, Engineering, Barriers, Degrees, Remedies

Paper type Research paper

(C) Shriyangi Aluwihare and Shammi De Silva. Published in the Asian Association of Open Universities. This article is published under the Creative Commons Attribution (CC BY 4.0) licence. Anyone may reproduce, distribute, translate and create derivative works of this article (for both commercial and non-commercial purposes), subject to full attribution to the original publication and authors. The full terms of this licence may be seen at: http://creativecommons. org/licences/by/4.0/legalcode

The authors would like to acknowledge the invaluable contributions made by Professor S.A. Ariadurai, Nadeesha Abeysekera and Wasana Sirisena. 


\section{Introduction}

Faculty of Engineering Technology (FET) at the Open University of Sri Lanka (OUSL), the only national university, offers engineering programmes via open and distance learning (ODL) in Sri Lanka. The faculty has completed 30 years of existence and has produced graduates in the disciplines of agriculture, civil, mechanical, mechatronics, computer, electrical, electronics and communication engineering and in industrial studies in agriculture, textile manufacture and apparel technology.

As widely accepted, engineering education is the most difficult to teach as a distance learning course as it needs hands-on experience with machines (Ariadurai and Manohanthan, 2008). The FET, being one of the pioneers among all academic institutions of the world in delivering engineering programmes in distance education mode, adopts competitive pedagogical methods and tools for efficient and effective learning outcome. The structure of ODL provided by FET facilitates the learner community with the greatest possible control over time, place and pace of engineering education. Thereby, FET could reach the industry personnel who are experienced but lack the theoretical background in various areas of engineering. Keeping par with the technological developments, FET provides students with learner support via modern day technologies such as online support through the "OUSL Learner Management System", video conferencing by linking the main campus to number of regional and study centres, conducting online examinations, utilizing contemporary laboratories, etc.

Although FET has taken maximum effort to deliver the programmes in a competitive way, it has been observed that the students following bachelor's degree programmes offered by the FET of the OUSL take extraordinarily longer period to complete their degrees. A significant number of students have taken more than 10-15 years to complete the four- and five-year degree programmes. The problem of late completion of programmes in distance education has been subjected to considerable investigation (Musingafi et al., 2015; Berge et al., 2002). Late completion of the programmes is due to the underlying challenges faced by the ODL students. Berge $e$ t al. (2002) classified challenges to distance learners as situational-, epistemological-, philosophical-, psychological-, pedagogical-, technical-, social- and cultural-related challenges. Kember (1989) suggested that poor time management leads to challenges such as learners' inability to integrate the demands of off-campus study with family, work and social commitments. According to Zirnkle (2001), the barriers that an ODL learner faces are programme costs, lack of equipment and infrastructure, instructional concerns, poor technical assistance, inadequate feedback and poor teacher contact, alienation and isolation and poor student support services. Mossberger et al. (2003) was of the view that technical competence needed in order to have an effective access to contemporary ICT is a challenge to a distance learner.

In recent years, discussions have taken place in the FET of the OUSL on the prolonged time taken for the completion of the degrees offered by the faculty. This research was conducted primarily to identify the institutional barrier, student-related personal barrier and psychological barrier behind the prolonged duration for the completion of the said degrees. As a secondary goal, remedial measures that can be used to improve the duration of the degree programmes have been identified.

\section{Degree programmes}

Bachelor of Technology (Engineering) (BTech) and Bachelor of Industrial Studies (BIS) are the two degree programmes offered by the FET. These degrees are designed in accordance with the requirements of the Sri Lanka Qualification Framework and are
Time taken

to complete

the degree

programmes 
AAOUJ 11,2

recognized both academically as well as professionally. The BTech (Engineering) degree of the OUSL is recognized by the Institution of Engineers Sri Lanka as a fulfilling academic qualification for associate membership. Furthermore, the BTech (Engineering) degree is equivalent to the engineering degrees offered by other national universities (Student Guide Book, 2014).

Entry requirement

Three passes in the General Certificate in Education (Advanced Level) in the physical science stream is the basic entry requirement for the BTech (Engineering) degree programme. Anyone who possesses three passes in the General Certificate in Education (Advanced Level) in any stream is allowed to join for the BIS degree programme. Students with higher qualifications in technology are entered to the programmes in relevant intake points.

\section{The study system}

The central component of the study system by the FET is the printed course material prepared by the relevant academics of the OUSL that offers the students information equivalent to lectures in a conventional university. They also provide a series of carefully designed activities and self-assessment questions, which help the student to develop analytical skills and independent thought. Printed material is supplemented by audio-visual material, online classes, face-to-face discussions/clarification classes (day schools), tutor clinics, laboratory work, mini projects (MP), fieldwork, field visits, viva voce examinations and seminars. Laboratory work and fieldwork form an integral part of most courses in technology and are compulsory. By offering FET programmes via the OUSL centre network that is spread all over the island, the barrier of distance is thought to be greatly reduced.

\section{Assessment criteria}

Each course in a programme of study is assessed separately. Assessment consists of two components, namely, continuous assessment (CA) and final examination (FE). CA is not merely a means of assessment, it is one of the significant means of facilitating learning. Activities such as laboratory work, field classes, tutor marked assignments, presentations, MP and CA tests are integral part of learning and assessment. A student is required to obtain a minimum of 40 per cent marks in CA of a particular course to be eligible to sit for the FE. If this minimum mark is not obtained, the student is considered to have failed in that course and has to re-register in a subsequent year. In this event, the student can obtain only a simple pass (C grade) for the course after successful completion.

A student gaining eligibility in a particular course is expected to sit the FE in the same year. However, facing the FE may be postponed to a subsequent year, within the valid period of eligibility of up to a maximum of three academic years including the year the student obtained the eligibility. Final assessment mark of any course depends on the performance at both the CA and the FE. For the courses offered by the Faculty, these components carry equal weight. Therefore, students must practice continuous learning throughout the academic year in order to attain success. Since a fair proportion of the activities used to impart knowledge in distance education have to be carried out by the student, success is possible only if he/she is motivated to learn by himself/herself. A student failing to obtain eligibility to sit the FE for any course will have to re-register for that course in a subsequent year by re-paying the tuition fee. 
Such a student will be considered as a repeat student for that particular course. Such students will not be eligible for a grade higher than $\mathrm{C}$ grade for the repeat course, depending on the programme (Student Guide Book, 2014).

Counsellors at the time of registration strongly recommend that a student only register for the number of courses which they can manage within their respective time availability. A student who obtains the eligibility for a particular course but fails to obtain the minimum pass mark at the FE will be considered as a re-sit student. Re-sit students are not required to re-register for that particular course; however it is important that such students sit the FE before the eligibility period expires. Re-sit students will also not be eligible to obtain a higher grade than a mere pass grade (grade $\mathrm{C}$ ).

\section{Requirements for the award of degrees}

Both study programmes in technology and industrial studies consist of four academic levels where the students are expected to enrol for courses from different categories. The course categories included in the technology curriculum are engineering, engineering projects, mathematics, general, management, industrial training, English language and computer literacy. The industrial studies programme consists of courses from categories such as industrial, management, general, mathematics, projects, English language, industrial training and computer literacy. The students are allowed to register for a maximum of 45 credits per academic year which is equivalent to 1,125 notional learning hours. The total course credit requirements for the award of BTech (Engineering) and BIS degrees are 177 and 150, respectively. The credit requirement is subjected to certain conditions so that a pre-determined minimum should be obtained from different categories and levels. In addition, the students need to complete industrial training modules equivalent to 30 weeks of duration according to the respective field of specialization (Student Guide Book, 2014).

\section{Methodology}

The research design involved extracting a sample of graduates from FET and distribution of a structured questionnaire among them. Exploratory interviews with the easily contactable graduates from FET were conducted before developing the questionnaire.

\section{Exploratory interviews}

The interviews were conducted individually and in groups of two based on the preference of the participants and their time constraints. A total of seven interviews were conducted with 17 graduates, ensuring participation from both BTech and BIS graduates.

The interviews addressed issues related to challenges associated with ODL, barriers arising due to quality of learner support, learners scholarly abilities, required academic skills, time and motivation factors and personal and psychological barriers faced by each individual.

\section{Questionnaire}

A structured questionnaire was developed using the data gathered during exploratory interviews and observations made by the first author who has served as a Senior Lecturer at the FET for a period of 13 years. The questionnaire included open-ended questions, yes or no questions and questions and statements with five-point Likert scale.
Time taken

to complete the degree programmes

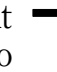


AAOUJ

11,2

The questionnaire assessed the perceptions of the graduates of FET regarding their prolonged duration for the completion of the said degrees on the following points:

(1) Institutional barriers:

- poor academic counselling and guidance;

- inappropriateness of course material/course material being not updated;

- laboratory sessions being inappropriate/not sufficient to understand course material;

- inadequate resources and facilities such as library resources, computer and internet facilities, poor teaching and learning environments;

- lack of laboratory facilities at the regional/study centre network;

- high standard expected for the final-year project;

- timely conveyance of eligibility expired in three years;

- timely conveyance of registration information, course offerings, changes to course schedules and examination schedules; and

- quality of instruction and effectiveness of day schools.

(2) Student-related personal barriers:

- work-related challenges;

- travelling time and cost of commuting to the main centre of the centre network where most of the activities are carried out;

- inability to spend the required time expected of the programme;

- lack of time due to family commitments;

- cost of tuition fees;

- frustrated with the personal life which led to poor concentration on the programme;

- the living (home) environment was not suitable for studies;

- parallel registration with another degree/diploma programme;

- inability to add/drop courses during the given period; and

- difficulty in familiarizing with the new course delivery system using Moodle.

(3) Psychological barriers:

- possessing a limited repertoire of study strategies;

- lack of understanding of ODL methods;

- deficiency of constant motivation throughout the study period;

- lack of independent learning skills;

- lack of mathematical skills required by the programme; and

- knowledge of English was not up to the standard required by the programme. 
Remedial measures that can be adopted to improve the time taken to complete the degree programmes

The questionnaire also evaluated the observations of the graduates of FET regarding five remedial measures to improve the time taken to complete the said degree programmes. The suggested remedial measures can be listed as follows:

Time taken to complete the degree programmes

- shorten the duration of the degree programmes;

- adopt a semester system;

- conduct repeat examinations;

- adopt a methodology to re-correct FE papers; and

- equip regional centres with all necessary facilities.

The questionnaire was pilot tested, revised and administered among the selected sample of graduates.

Selecting the sample respondents

A sample of 284 respondents was drawn with the use of stratified random sampling method using the full sample frame of 956 graduates who have graduated during the period from 1986 to 2014 from FET.

\section{Data collection}

The questionnaires were posted/hand delivered to the selected sample of graduates and 166 responded.

\section{Results and discussion}

The duration for the completion of the degree programmes by the respondents was analysed, and after removing the outliers, it was found that more than 90 per cent of the students have taken 6-15 years to complete the four- and five-year degree programmes (Figure 1).

The results are presented under the following sub-sections: institutional barriers, student-related personal barriers and psychological barriers.

\section{Institutional barriers}

Results illustrated in Figure 2 indicate that 77 per cent of the respondents thought poor academic counselling and guidance have contributed immensely to their

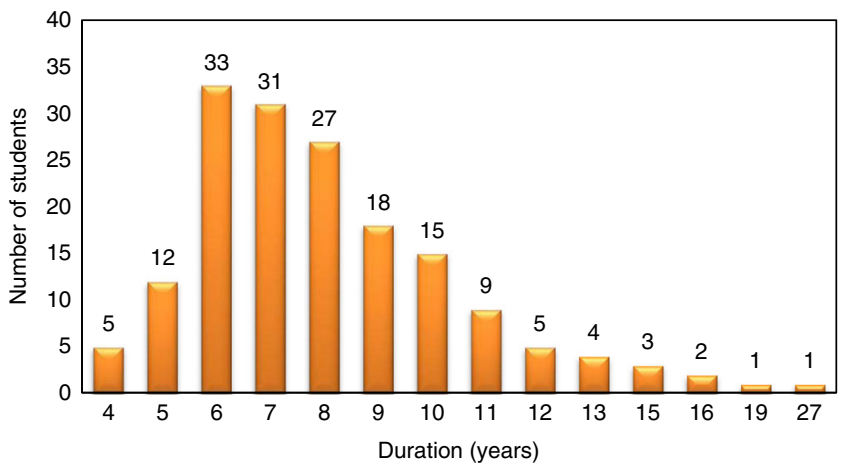

Figure 1.

Number of graduates vs respective duration for the completion of the degree programmes 
AAOUJ 11,2

142

prolonged duration to complete the degrees. Most students do not receive proper counselling at the time of registration as most registration activities are carried out by the clerical staff of the OUSL. Selecting unsuitable courses and inappropriate course loads can eventually lead to lengthening of the time duration. Of the respondents, 56 per cent were of the view that the laboratory sessions were inappropriate/not sufficient to understand the course material. In most laboratory sessions, the instruction sheets are given at the beginning of the laboratory session, where the students find it difficult to understand/correlate with the course materials. Among the respondents, 67 per cent are of the view that inadequate resources and facilities such as library resources, computer and internet facilities and poor teaching and learning environments have contributed much to the lengthy duration of the degree programmes. From the respondents, 78 per cent believed that the lack of laboratory facilities at the regional/study centres has contributed greatly to the prolonged duration taken to complete the degrees. Laboratory facilities for higher level courses are available only in the Colombo Regional Centre (Aluwihare and Manoshika, 2013). Learners from other regions have to travel to Colombo and find accommodation to participate in the laboratory classes, and thus many employed students give up the laboratory component of the courses (which is compulsory) as they cannot spend the time needed for the above venture.

Other factors tested under "institutional barriers" such as inappropriateness of course material, high standard expected for the final-year project, poor quality of instruction and effectiveness of day schools and delayed conveyance of eligibility expired in three years were found to be less important issues for the prolonged completion of the degree programmes as shown in Figure 3.

\section{Student-related personal barriers}

As illustrated in Figure 4, personal factors such as work-related challenges have hindered the on-time completion for more than 60 per cent of the graduates. The flexibility in the programme structure provides learners to be employed while studying in the OUSL - FET. Therefore, most students are found to be employed at the time of graduation. Employed students find it difficult to obtain leave for some of the compulsory activities and find it hard to concentrate fully on the programme due to the duties vested on them. Work-related challenges are more on students working

Figure 2.

Institutional barriers rated as significant for on-time completion of the degree programmes

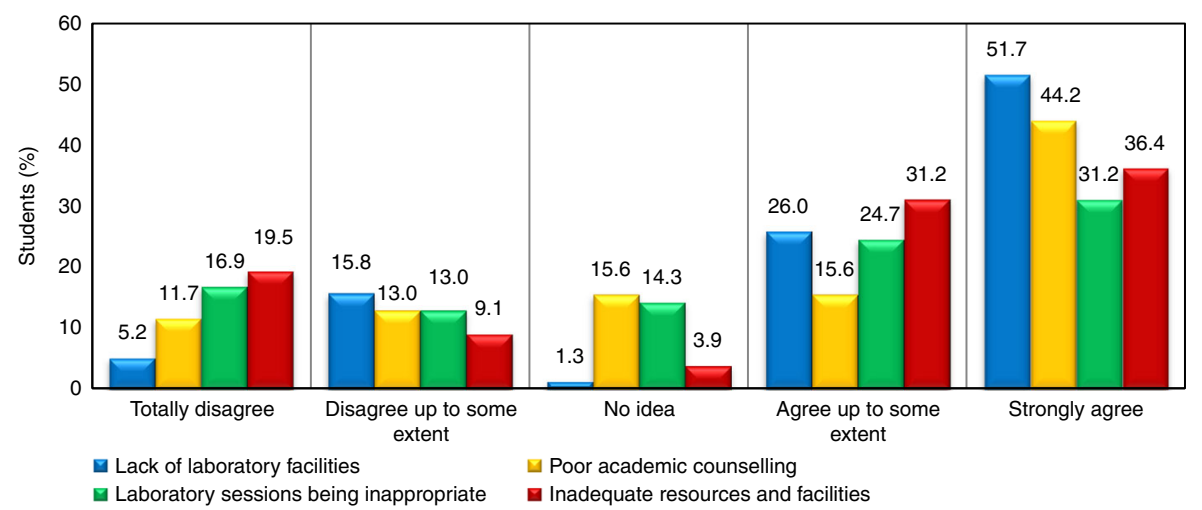


in the private sector than in government institutions (Dedigamuwa and Senanayake, 2012). It is apparent from Figure 3 that 64 per cent of the respondents considered the travelling time and cost of commuting to the main centre located in Colombo have contributed hugely to the prolonged duration for the completion of the degree programme. This factor plays a major role for students living away from the main centre. For example, a student living in Kandy who wishes to attend a day school of a duration of two hours should spend at least eight hours of travel time to Colombo and back home in Kandy. Therefore, most students from regions other than Colombo do not attend the face-to-face sessions conducted by the OUSL teachers. Of the respondents, 57 per cent have reported that their inability to spend the required time expected of the programme has lengthened the duration of the programme whereas 40 per cent of the respondents rated against it. Mainly employed students failed to allocate the time required to follow the course effectively. On the other hand, unemployed young students with successful secondary education are able to spend plenty of time on the degree programmes for on-time completion (Hill, 2009). For 63 per cent of the respondents, the cost of tuition is not a major barrier for on-time completion.

Other personal factors such as family commitments, frustration which led to poor concentration on the programme, the living (home) environment not suitable for studies, parallel registration with another degree/diploma programme, inability to
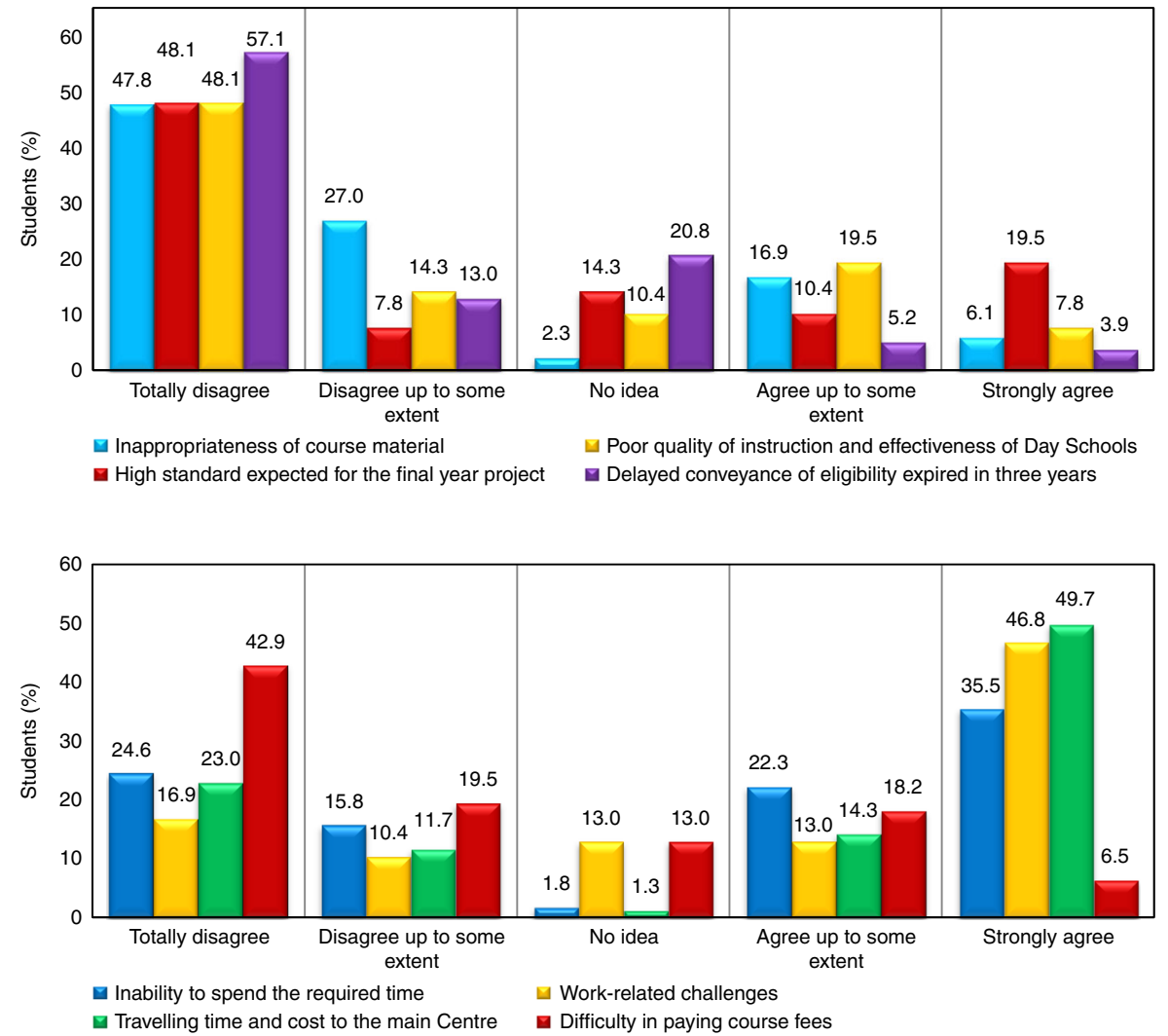

Time taken to complete the degree programmes
Figure 3. Institutional barriers rated as insignificant for on-time completion of the degree programmes
Figure 4.

Student-related personal barriers rated as significant for on-time completion of the degree programmes 
AAOUJ 11,2

144
Figure 5.

Student-related personal barriers rated as insignificant for on-time completion of the degree programmes
Figure 6.

Psychological barriers rated as significant for ontime completion of the degree programmes add/drop courses during the given period, difficulty in familiarizing with the new course delivery system using Moodle, etc., were ranked as less important issues when it came to on-time completion of the degree programmes as shown in Figure 5.

\section{Psychological barriers}

According to Figure 6, 58 per cent agreed that possessing a limited repertoire of study strategies have lengthened their degree programme. Most learners use primitive strategies to help them remember course material but not to understand them (Hill, 2009). Most use crash lessons called "kuppi" classes conducted by one of the peers just before the examinations to remember the important course content. About 86 per cent of the learners agreed that lack of understanding of ODL methods has contributed immensely to the increased time duration for their degree programmes. The learners do not understand the difference between a conventional lecture and a day school. Most learners turn up for day schools with minimal preparation which reflects a lack of understanding of ODL objectives rather than lack of effort. The learners overall attitude towards ODL was poor as they always compare it with conventional system of course delivery. Most learners do not understand that the main medium of bridging the gap between the teacher and the student is the printed course materials. Among the learners, 66 per cent were of the idea that the deficiency of constant motivation
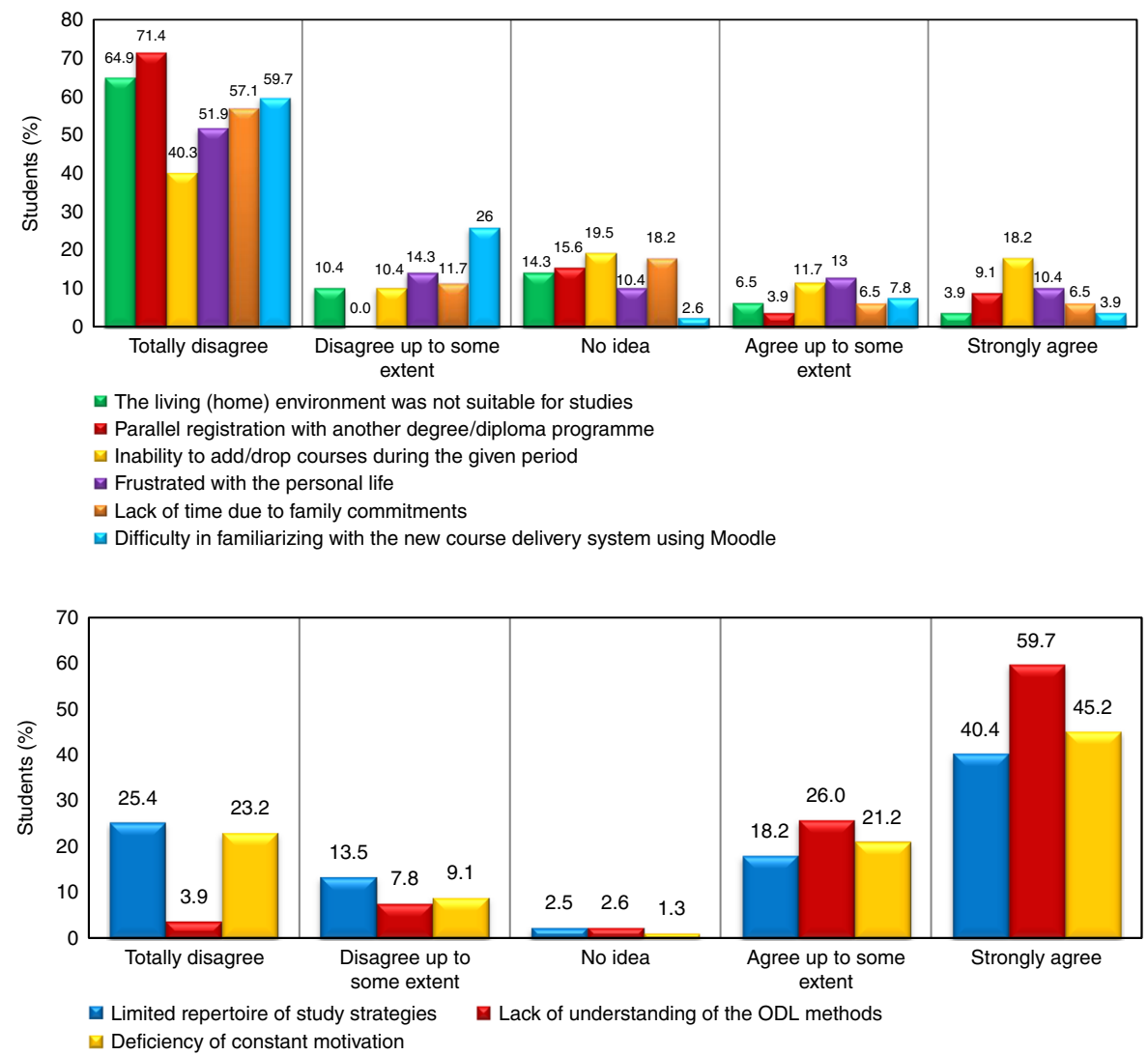
throughout the study period had a tremendous impact on the delayed graduation. Degree programmes offered by FET need more learner commitment and self-motivation as the learner is not always in an academic environment compared to conventional universities.

Other psychological barriers such as lack of independent learning skills, lack of mathematical skills required by the programme and knowledge of English not up to the standard required by the programme had less impact on the prolonged duration taken to complete the degrees as shown in Figure 7.

Although inadequate knowledge in English and mathematical skills should have been a strong factor for the lengthy time duration to complete the degrees, majority of respondents considered them as less important issues.

\section{Tools used in delivering the degree programmes}

High satisfaction rate of nearly 80 per cent was observed regarding the ODL tools that were used within the programmes and the formative and summative evaluation criteria, which are shown in Figure 8.

Graduates perspective on the remedial measures that can be used to improve the duration of the degree programmes

More than 80 per cent of the sample approved the suggested remedial measures of adopting a semester system (Figure 9), conducting repeat examinations (Figure 10) and shortening the duration of the completion of the degree programmes (Figure 11). More than 64 per cent approved the adoption of a methodology to re-correct FE papers (Figure 12) and equipping regional centres with all necessary facilities (Figure 13).
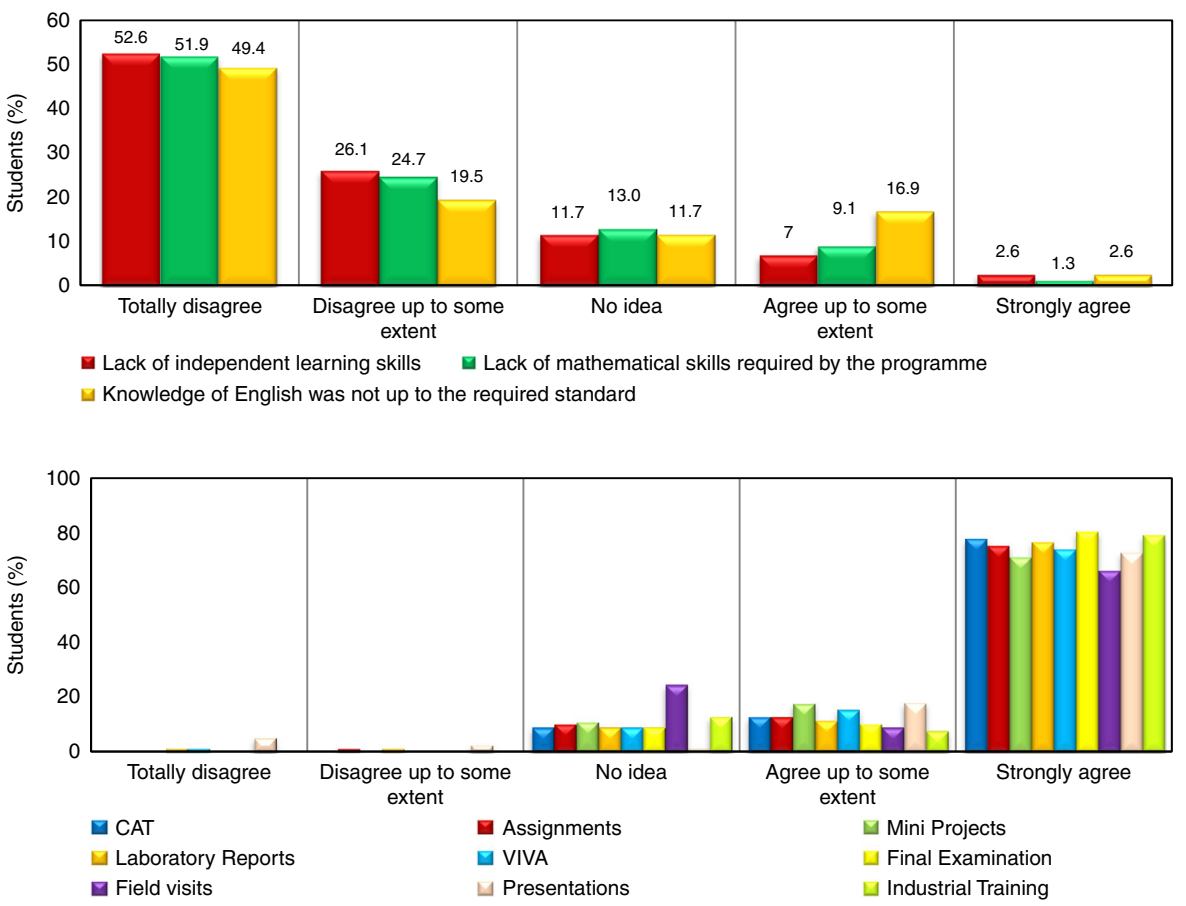

Time taken to complete the degree programmes
Figure 7.

Psychological barriers rated as insignificant for ontime completion of the degree programmes
Figure 8.

Learner satisfaction rates regarding ODL tools and formative/ summative evaluation criteria used within the programmes 


\section{AAOUJ \\ 11,2}

146

Figure 9.

Adopting a semester system

Figure 10.

Conducting repeat examinations

\section{Figure 11.}

Shortening the duration of the degree programmes
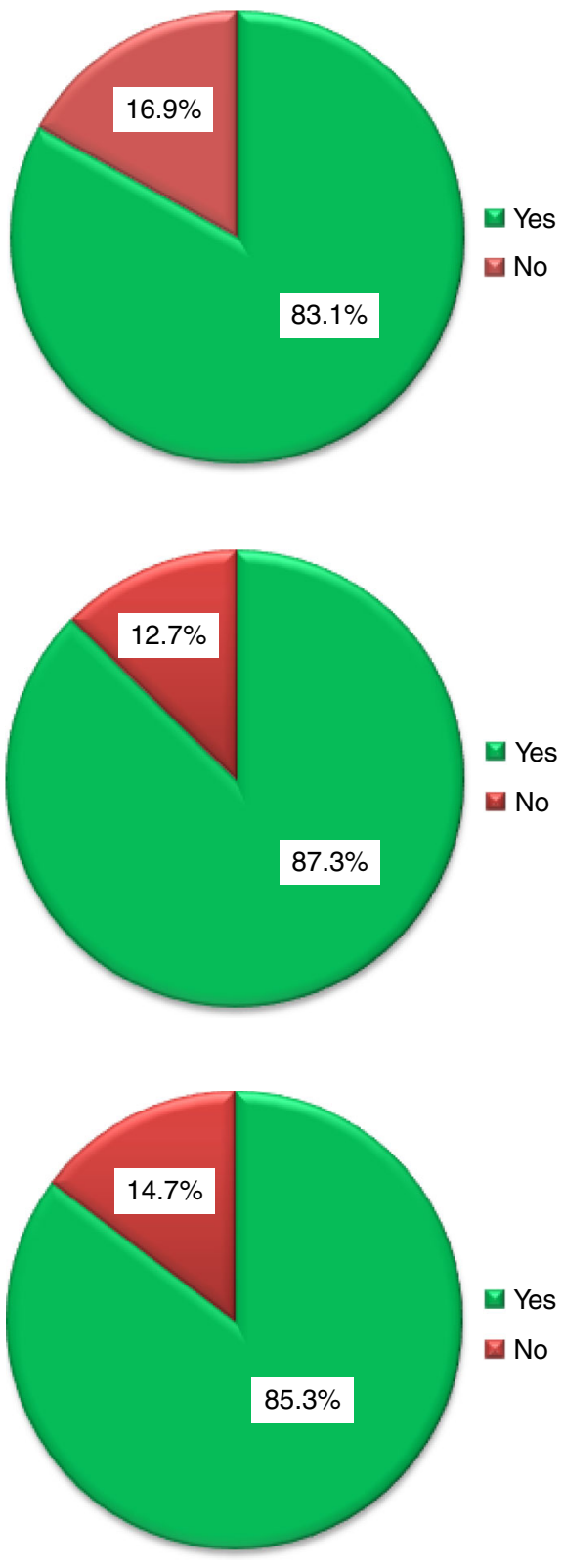

\section{Conclusions and recommendations}

Findings of this study provide some insights for shortening the duration of the BTech and BIS degree programmes offered by the OUSL. Institutional barriers such as poor academic counselling and guidance, laboratory sessions being inappropriate/not sufficient to understand the course material, inadequate resources and facilities such as library resources and computer and internet facilities, poor teaching and learning 


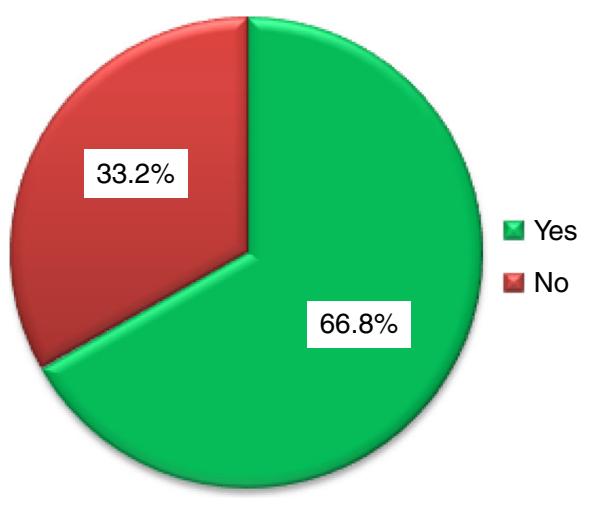

\section{Time taken \\ to complete \\ the degree \\ programmes}

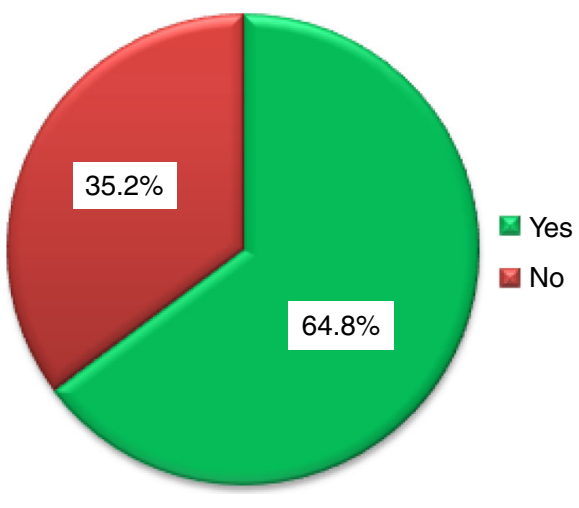

Figure 13.

Equip regional centres with all necessary facilities

environments and lack of laboratory facilities at the regional/study centres have contributed immensely to the lengthy duration taken to complete the degrees. But the institutional barriers can be easily overcome by strengthening the centre network that will enhance learner support and updating and upgrading of laboratory facilities. Counselling at the time of registration for each academic year should be carried out by the teachers of FET, and proper guidance should be given in selecting appropriate course loads. Personal factors such as work-related challenges, travelling time and cost of commuting to the main centre located in Colombo and inability to spend the required time expected of the programme have played major roles on the prolonged completion of the degree. Results indicate that the cost of tuition is not a major barrier for on-time completion. Psychological barriers such as possessing a limited repertoire of study strategies, lack of understanding of ODL methods and deficiency of constant motivation throughout the study period had a tremendous impact on the delayed graduation. Personal barriers can be alleviated by molding the learners to be good time managers and independent learners with strong focus. Providing the learner with a greater repertoire of study strategies may remove physiological barriers. All these can be achieved via "Student Orientations" which should be conducted with a strong focus on time management, developing academic skills and ODL methods. The remedies suggested for external means of shortening the duration of the degree programmes were well accepted by the respondents. 
AAOUJ

11,2

148

\section{References}

Aluwihare, P.S.D. and Manoshika, R. (2013), "Addressing the issues of low student enrollment the case of the Kandy Regional Centre of the Open University of Sri Lanka”, Journal of Asian Association of Open Universities, Vol. 8 No. 1, pp. 103-115.

Ariadurai, S.A. and Manohanthan, R. (2008), "Reasons for student discontinuation in engineering degree courses offered at a distance", Turkish Online Journal of Distance Education, Vol. 10 No. 1, pp. 171-181.

Berge, Z.L., Muilenburg, L.Y. and Haneghan, J.V. (2002), "Barriers to distance education and training: survey results”, The Quarterly Review of Distance Education, Vol. 3 No. 4, pp. 409-418.

Dedigamuwa, P.R. and Senanayake, S.A.M.A.N.S. (2012), "Motivating factors that affect enrollment \& student performance", The International Review of Research in Open and Distance Learning, Vol. 13 No. 1, pp. 238-249.

Hill, C.M. (2009), "Opening doors for learners; barriers and challenges at the Open University of Sri Lanka”, OUSL Journal, Vol. 5 No. 1, pp. 3-21.

Kember, D. (1989), “A longitudinal-process model of drop-out from distance education”, Journal of Higher Education, Vol. 60 No. 3, pp. 278-301.

Mossberger, K., Tolbert, C. and Stansbury, M. (2003), Virtual Inequality: Beyond the Digital Divide, Georgetown University Press, Washington, DC.

Musingafi, M.C.C., Mapuranga, B., Chiwanza, K. and Zebron, S. (2015), "Challenges for open and distance learning (ODL) students: experiences from students of the Zimbabwe Open University", Journal of Education and Practice, Vol. 6 No. 18, pp. 59-66.

Student Guide Book (2014), Student Guide Book, Faculty of Engineering Technology, the Open University of Sri Lanka, OUSL Publication, Colombo.

Zirnkle, C. (2001), “Access barriers in distance education”, Contemporary Education, Vol. 72 No. 2, pp. 39-42.

\section{Corresponding author}

Shriyangi Aluwihare can be contacted at: shriyangia@yahoo.com

For instructions on how to order reprints of this article, please visit our website:

www.emeraldgrouppublishing.com/licensing/reprints.htm

Or contact us for further details: permissions@emeraldinsight.com 